\title{
Vibrational Spectroscopic Analysis of Body Fluids: Avoiding Molecular Contamination Using Centrifugal Filtration
}

\author{
Franck Bonnier \\ Technological University Dublin \\ Matthew Baker \\ University of Central Lancashire \\ Hugh Byrne \\ Technological University Dublin, hugh.byrne@tudublin.ie
}

Follow this and additional works at: https://arrow.tudublin.ie/biophonart

Part of the Biochemistry Commons, and the Physics Commons

\section{Recommended Citation}

Bonnier, F., Baker, M.J. \& Byrne, H.J. (2014) Vibrational spectroscopic analysis of body fluids: avoiding molecular contamination using centrifugal filtration, Analytical Methods, 6, 5155. DOI: 10.1039/ C4AY00891J

This Article is brought to you for free and open access by the DIT Biophotonics and Imaging at ARROW@TU Dublin. It has been accepted for inclusion in Articles by an authorized administrator of ARROW@TU Dublin. For more information, please contact arrow.admin@tudublin.ie, aisling.coyne@tudublin.ie,gerard.connolly@tudublin.ie. Funder: SFI 
Dublin Institute of Technology

ARROW@DIT

Articles

2014

Vibrational spectroscopic analysis of body fluids: avoiding molecular contamination using centrifugal filtration

Franck Bonnier

Matthew J. Baker

Hugh J. Byrne

Follow this and additional works at: http:/ /arrow.dit.ie/despart

Part of the Art and Design Commons, Biochemistry, Biophysics, and Structural Biology Commons, and the Medical Biotechnology Commons

This Article is brought to you for free and open access by ARROW@DIT. It has been accepted for inclusion in Articles by an authorized administrator ofARROW@DIT. For more information, please contact

yvonne.desmond@dit.ie, arrow.admin@dit.ie. 
Vibrational spectroscopic analysis of body fluids: avoiding molecular contamination using centrifugal filtration

\author{
Franck Bonnier ${ }^{1}$, Matthew J. Baker ${ }^{2}$, Hugh J. Byrne ${ }^{1}$
}

1. Focas Research Institute, Dublin Institute of Technology (DIT), Camden Row, Dublin 8, Ireland

2. Centre for Materials Science, Division of Chemistry, University of Central Lancashire (UCLan), Preston PR1 2HE, UK

*Corresponding Author: Franck Bonnier,

Focas Research Institute, Dublin Institute of Technology,

Kevin Street, Dublin 8, Ireland.

E mail address: fbonnier@dit.ie

Ph: +35314027917

Fax: +353 14027904 


\begin{abstract}
The use of centrifugal filtration for protein purification and concentration represents an important improvement for the application of vibrational spectroscopy to analysis of bodily fluids based on protein fractions with specific molecular weight. Vibrational spectroscopic techniques are highly specific and can potentially detect small variations in the protein content indicating the presence of different diseases, therefore usable as markers for early diagnostic. However, due to the high sensitivity of the techniques, it is essential to verify that no molecular contamination occurs during the preparation of the samples. Concentration of the blood serum using commercially available centrifugal filters has been shown to result in an improvement in the spectral intensity and quality. However, the presence of contaminant features, identified as deriving from glycerine, can be found in the data collected after use of the centrifugal filters. It is demonstrated in the present work that careful washing of the filters is required before the analysis of body fluids based on concentrated samples. The demonstrated protocols for spectroscopic measurement of human serum are applicable to a range of bodily fluids and should accelerate potential clinical applications.
\end{abstract}

Keywords: Vibrational spectroscopy, ATR spectroscopy, bodily fluids, human serum, centrifugal filtration, glycerol, filter washing. 


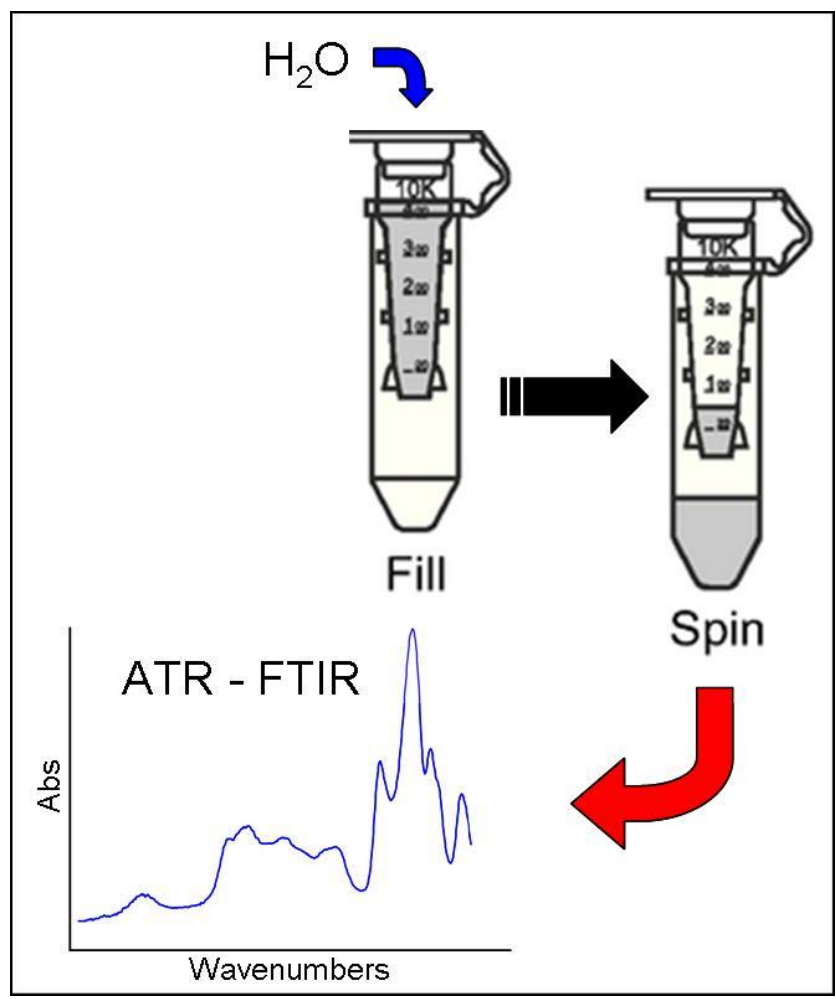

Graphical abstract: Problem of molecular contamination associated with centrifugal filters for analysis of human body fluids using vibrational spectroscopy 


\section{Introduction}

The potential of vibrational spectroscopy, both Fourier transform Infrared (FTIR) and Raman, has been widely investigated for diagnostic purposes in cells and tissue analysis and the feasibility to use them for disease diagnostics has been extended to a wide range of bodily fluids ${ }^{1}$ ranging from serum ${ }^{2-5}$ to tears ${ }^{6,7}$ urine and saliva ${ }^{8-10}$. The past decade has seen significant development of both modalities for molecularly specific analysis on the micron and even nanoscale ${ }^{11-17}$. Analysis of bodily fluids for diagnosis and health monitoring presents a less invasive approach than performing biopsies of organs for example during cancer screening ${ }^{18}$. In this context, blood serum presents a promising candidate for the application of vibrational spectroscopy, as the analysis of the proteins present in the blood stream can potentially deliver crucial information on patient health and indicate the presence of numerous pathologies ${ }^{19}$. Blood serum contains $>20,000$ different proteins, ranging from 50 g.L - $^{-1}$ (serum albumin) ${ }^{20,21}$, to less than $1 \mathrm{ng} . \mathrm{L}^{-1}$ (troponin) ${ }^{22}$, with an overall protein concentration of $\sim 1 \mathrm{mM}$. Although other components such as lipids (lipoproteins) can also be found, protein sensing remains the main challenge for diagnostic purposes. The low molecular weight fraction of the serum, referred to by the term "peptidome", is of particular interest for the potentially rich cancer-specific diagnostic information it contains $^{23,24}$. Bound to high-abundance proteins such as albumin, it represents a fingerprint of the molecular events taking place within different organs or tissues related to the presence of cancers but also modification to their close microenvironment $^{25,26}$. Therefore, the analysis of protein imbalances in the serum can be directly related to, and indicative of, disease states ${ }^{27-30}$. 
In both Infrared and Raman spectroscopic studies, to date the analysis has predominantly been performed on air-dried drops of serum deposited on spectroscopically neutral substrates such as $\mathrm{CaF}_{2}{ }^{31,}{ }^{32}$. The main reasons are the relatively low concentration of analytes in the serum, leading to poor signal to noise ratios (Raman spectroscopy) or the strong contribution of water in the spectra collected (Infrared spectroscopy). Such dried deposits are, however, extremely chemically and physically inhomogeneous and can lead to spectral saturation (in transmission or transflectance FTIR) or high variability in spectral recordings in point mapping modes of Raman or FTIR, requiring rigorous and lengthy sampling and averaging procedures. Moreover, using FTIR in transmission mode, in order to collect a spectrum, the serum is diluted $2 / 3$ fold leading to longer sample preparation procedures and drying times with the possible introduction of external contaminants. ATR spectroscopy (Attenuated Total Reflection) is a particularly interesting alternative for the application of FTIR to body fluids analysis ${ }^{33}$, as in this mode the sampling should average over the whole film in a single acquisition. It generally requires less than $10 \mu \mathrm{L}$ to be deposited on the ATR crystal, which is then air dried to reduce the water contribution in the data collected. Due to the extremely small volume used, only a few minutes are necessary to obtain a thin dry biofilm that can be recorded ${ }^{24,34}$.

More recently, the use of commercially available centrifugal filters has emerged as an alternative strategy which allows concentration of the blood serum proteins resulting in an improvement in the spectral intensity and quality ${ }^{35}$. Moreover, it presents the possibility to rapidly separate protein fractions with different molecular weight according to the cut-off points selected, which can considerably improve the 
sensitivity of disease detection by removing the most abundant high molecular weight proteins, thus revealing spectral features usually hidden from the less abundant low molecular weight molecules ${ }^{36-38}$. It is likely that such centrifugal devices will become increasingly popular for applications of vibrational spectroscopy to analysis of bodily fluids and already preliminary work can be found in the literature ${ }^{24,34}$ However, many concerns have to be addressed before being able to evaluate their benefits for diagnostic purposes. The high sensitivity of the vibrational techniques is often used as an argument for their potential to visualize minor modifications in the molecular profiles from different samples. Therefore, the techniques have the capacity to detect and identify biomarkers specific of different pathologies. However, although vibrational spectroscopies are label free techniques, some requirements regarding the sample preparation have to be considered to collect relevant data. The high sensitivities also mean that any trace impurities introduced in the samples during the preparation process, for example centrifugation or filtration, could also contribute significantly to the spectral profiles collected. In the present work, it is demonstrated that, prior to blood serum analysis, it is essential that the centrifugal filters are thoroughly washed in order to avoid contamination of the samples by molecules present in the as-delivered filter membrane. Although the application of vibrational spectroscopy to human serum has been taken as an example, the same considerations apply to analysis of any of the human bodily fluids by such methods.

\section{Materials and Methods}

\subsection{Sample preparation}


Sterile filtered human serum from normal mixed pool (off the clot) was purchased from TCS Biosciences (Ireland). Commercially available centrifugal filtering devices, Amicon Ultra-0.5ml (Millipore - Merck, Germany), with cut-off points at 100K and $10 \mathrm{~K}$, were employed in this study as examples.

At first, $0.5 \mathrm{~mL}$ of the serum was placed in the $100 \mathrm{~K}$ centrifugal filtration device, whith no washing, and centrifuged at $14,000 \mathrm{x}$ g for $30 \mathrm{mins}$. The filtrate obtained from the $100 \mathrm{~K}$ device was then centrifuged using the $10 \mathrm{~K}$, under identical conditions. The filter devices were then placed upside down in a new Eppendorf and spun down at $1000 \mathrm{~g}$ for 2 mins in order to collect the remainder of the serum (concentrate) retained in the filter devices. The concentrating factor is of the order of 10 , with a resultant concentrate volume of $\sim 50 \mu \mathrm{L}$. As a result, 2 fractions were obtained; the first representing proteins with a molecular weight higher than $100 \mathrm{~K}$; the second corresponding to the fraction between $100 \mathrm{~K}$ and $10 \mathrm{~K}$.

As indicated by the manufacturer, the ultrafiltration membranes in Amicon® Ultra0.5 devices "contain trace amounts of glycerine. If this material interferes with analysis, pre-rinse the device with buffer or Milli-Q® water. If interference continues, rinse with $0.1 \mathrm{M} \mathrm{NaOH}$ followed by a second spin of buffer or Milli-Q ${ }^{\circledR}$ water.” (http://www.millipore.com/catalogue/module/c82301\#1)

However, no recommendation of washing procedures are provided. This study demonstrates that optimised washing of the centrifugal devices prior to serum analysis was achievable by spinning the Amicon Ultra- $0.5 \mathrm{ml}$ once with a solution of $\mathrm{NaOH}$ (0.1M) followed by two rinses with Milli-Q water (Millipore Elix S). For both washing and rinsing, $0.5 \mathrm{~mL}$ of the respective liquid was added to the filters and the centrifugation was applied for 30 mins at $14000 \mathrm{~g}$ followed by a spinning with the 
devices upside down at $1000 \mathrm{~g}$ for 2 mins in order to remove any residual solution contained in the filter.

The $\mathrm{pH}$ of the $\mathrm{NaOH} 0.1 \mathrm{M}$ solution, Milli-Q water and 3 different buffer solutions (Fischer scientific) at $\mathrm{pH} 4, \mathrm{pH} 7$ and $\mathrm{pH} 10$ were recorded using both a $\mathrm{pH}$ meter (Sension Quality Electrodes, Hach Company, USA) and pH-Fix test strips (Macherey Nagel, Germany), the latter due to the small volumes obtained from the centrifugal filters. Different ranges of $\mathrm{pH}$ indicator strips were used (pH-Fix 0-14, $\mathrm{pH}-$ Fix 7.59.5, $\mathrm{pH}-$ Fix 6.0-7.7) for better accuracy in the $\mathrm{pH}$ measurements. The buffer solutions were used to correlate the exact $\mathrm{pH}$ measured with the $\mathrm{pH}$ probes and different tints of color obtained on the $\mathrm{pH}$ indicators.

Additionally, glycerine (glycerol) (BDH, Ireland) was analysed as a reference for the identification of molecular contamination during the centrifugation.

\subsection{FTIR Instrumentation: Data collection using the UATR}

ATR spectra were recorded with the Perkin Elmer Spotlight 400N Universal Attenuated Total Reflectance (UATR) accessory of the spectrometer, which employs a 9-bounce diamond top-plate for this analysis. Sample penetration is both wavenumber and sample dependent, but is typically of order $1 \mu \mathrm{m}$. In ATR mode, spectral data were the result of 4 scans, with a spectral resolution of $8 \mathrm{~cm}^{-1} .5 \mu 1$ of the different liquid samples were deposited on the crystal and left to dry for 10 mins prior to recording. A background spectrum was also recorded and automatically subtracted by the software. 


\section{Results}

The water contribution is a limiting factor for application of infrared spectroscopy to bodily fluid analysis due to the presence of a strong absorbance in the finger print region (figure 1C) ${ }^{35}$. Therefore, the protein features from the human serum are obscured and hardly identifiable, as can be seen in the ATR spectrum of a drop of serum, shown in Figure 1B.

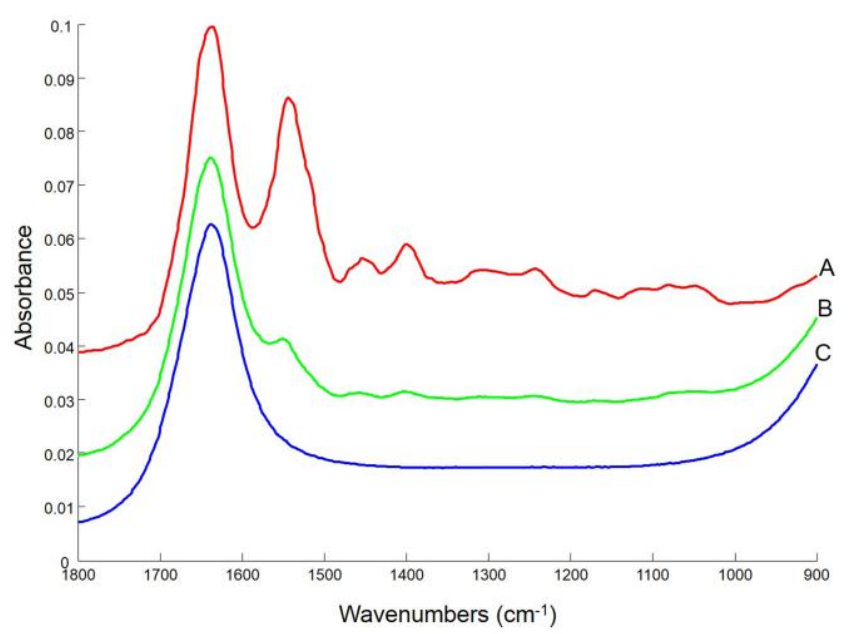

Figure 1: Infrared spectra collected using the UATR accessory. A: Whole human serum after 10 mins drying; B: Whole human serum before drying and $\boldsymbol{C}:$ Milli- $Q$ water. Spectra are offset for clarity

As the drop dries, however, the water features become less apparent, and the protein features more prominent, such that after 10 minutes drying, strong protein bands are identifiable in the fingerprint region, as shown in Figure 1A.

However, serum is a complex mixture and the highly abundant proteins dominate the spectral profile collected. Therefore, the use of centrifugal devices can greatly improve the sensitivity of the analysis by separating the different molecules according to their molecular weight $24,39,40$.

Figure 2 shows the spectrum of the dried complete serum sample (A), the $>100 \mathrm{~K}$ serum fraction (B), and the $<100$ Kserum fraction (D). Table 1 provides a list of band 
assignments ${ }^{41-47}$. Although the $>100 \mathrm{~K}$ serum fraction is very similar to that of the pure serum, consistent with the $>100 \mathrm{~K}$ fraction containing the most abundant proteins, the spectral profile of the $100 \mathrm{~K}-10 \mathrm{~K}$ fraction is significantly different, supporting the fractionation approach to provide more diagnostic information. However, the spectrum of the lower molecular weight fraction has strong contributions in the spectral region $\sim 1100 \mathrm{~cm}^{-1}-1000 \mathrm{~cm}^{-1}$, which are not readily attributable to expected serum components. Notably, when diluted by a factor of 10 , the spectrum of the $>100 \mathrm{~K}$ faction also shows the same features (Figure 2C). The spectra of the filtrates were taken from samples which were processed using unwashed centrifugal filter devices.

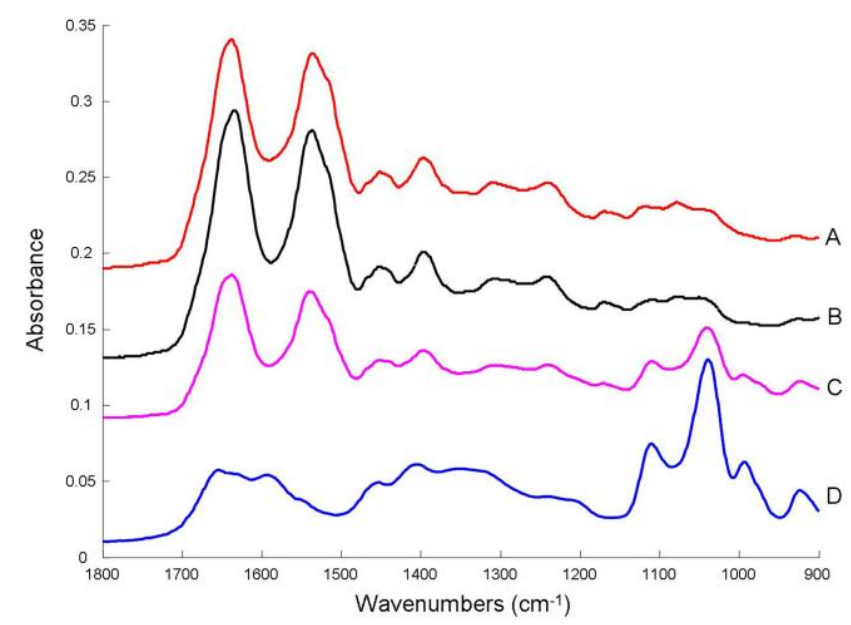

Figure 2: Infrared spectra collected using the UATR accessory 10 mins air drying following. A: Whole serum; B: Concentrate from human serum using an unwashed $100 \mathrm{~K}$ filter; $C$ : Concentrate from 1:10 diluted human serum using an unwashed 100K filter and D: Filtrate from human serum using an unwashed $100 K$ filter. 


\begin{tabular}{|c|c|}
\hline \multicolumn{2}{|c|}{ Human serum } \\
\hline Wavenumbers $\left(\mathrm{cm}^{-1}\right)$ & $\begin{array}{r}\text { Assignments } \\
\end{array}$ \\
\hline 3280 & H-O-H stretching \\
\hline 2957 & Asymmetric $\mathrm{CH}_{3}$ stretching \\
\hline 2920 & Asymmetric $\mathrm{CH}_{2}$ stretching \\
\hline 2872 & Symmetric $\mathrm{CH}_{3}$ stretching \\
\hline 1635 & $\begin{array}{l}\text { Amide I of proteins } v \mathrm{C}=\mathrm{O}(70-85 \%) / v \\
\mathrm{C}-\mathrm{N} / \delta \mathrm{N}-\mathrm{H}\end{array}$ \\
\hline 1537 & $\begin{array}{l}\text { Amide II of proteins } \delta \mathrm{N}-\mathrm{H}(40-60 \%) / \\
v \mathrm{C}-\mathrm{N}(18-40 \%)\end{array}$ \\
\hline 1453 & $\mathrm{CH}_{2}$ scissoring \\
\hline 1396 & $\mathrm{C}=\mathrm{O}$ stretch of $\mathrm{COO}-$ \\
\hline $1230-1330$ & $\begin{array}{l}\text { Amide III (N-H bend in plane and C-N } \\
\text { stretch) }\end{array}$ \\
\hline 1311 & $\mathrm{CH}_{2}$ twist \\
\hline 1242 & Asymmetric $\mathrm{PO}^{2-}$ stretch \\
\hline 1170 & Ester $\mathrm{C}-\mathrm{O}$ asymmetric stretch \\
\hline 1110 & $v(\mathrm{CN}) / \delta(\mathrm{CH})$ \\
\hline 1079 & $\mathrm{C}-\mathrm{O}$ stretch \\
\hline 1047 & $\mathrm{C}-\mathrm{O}$ stretch \\
\hline 926 & C-C-N backbone, $\mathrm{C}-\mathrm{C}$ stretch \\
\hline \multicolumn{2}{|c|}{ Glycerine } \\
\hline Wavenumbers $\left(\mathrm{cm}^{-1}\right)$ & Assignments \\
\hline 3282 & O-H stretching \\
\hline 2930 & C-H stretching \\
\hline 2881 & C-H stretching \\
\hline 1457 & C-O-H bending \\
\hline 1409 & C-O-H bending \\
\hline 1326 & C-H deformation \\
\hline 1237 & $\mathrm{CH}_{2}$ twisting \\
\hline 1108 & C-O stretching \\
\hline 1030 & C-O stretching \\
\hline 993 & C-O stretching \\
\hline 922 & $\mathrm{O}-\mathrm{H}$ bending \\
\hline
\end{tabular}

Table 1: Band assignments for prominent FTIR peaks in Human serum and glycerine ${ }^{34-40}$.

A comparison of the infrared spectra collected from the serum filtered using unwashed Amicon centrifugal filters with the spectra obtained for Milli-Q water processed with similar unwashed devices clearly demonstrates that the features observed are not related to the protein content of the serum but are due to a contamination of the samples during the filtration process (Figure 3A and 3B). 

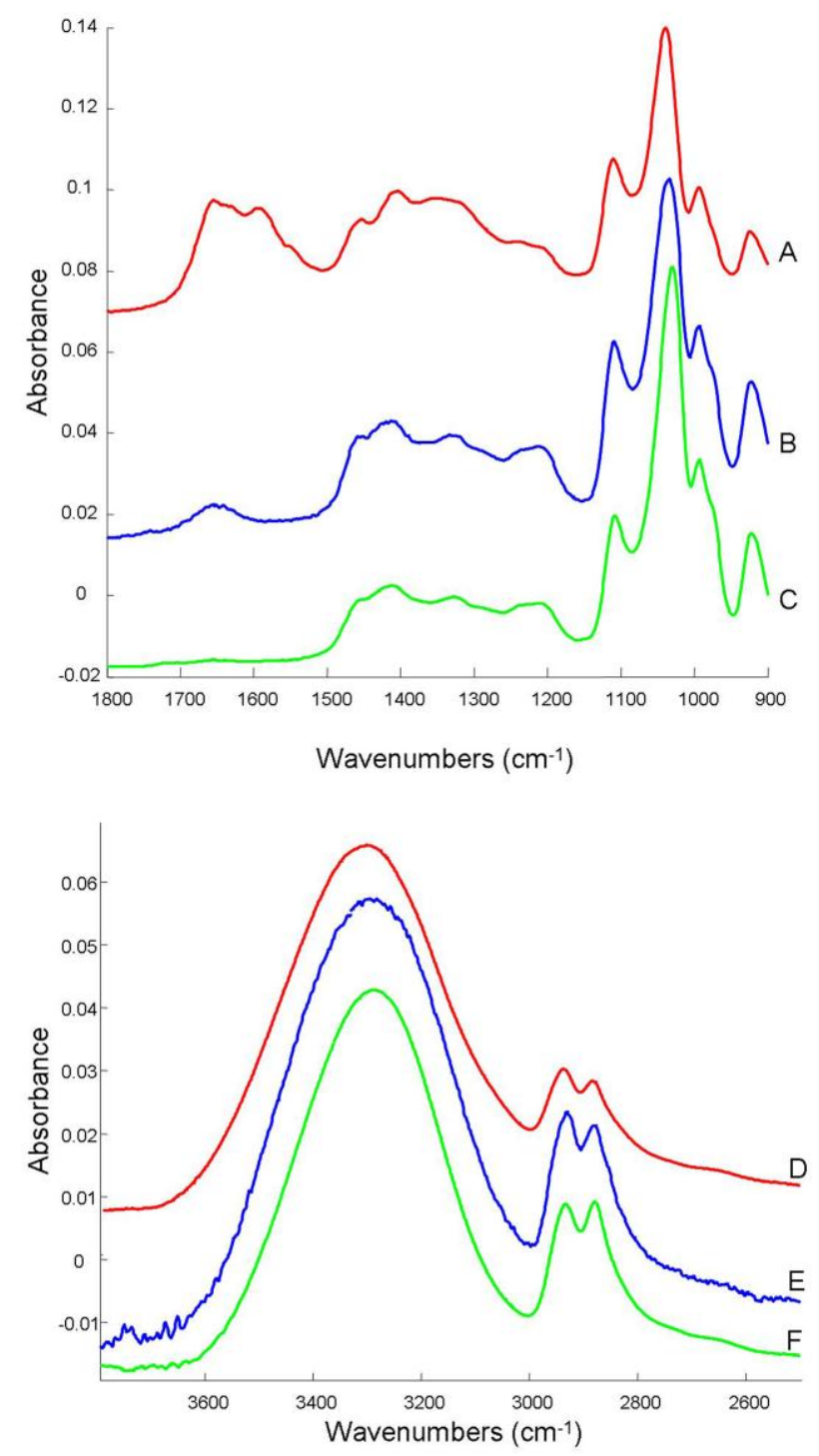

Figure 3: Infrared spectra collected using the UATR accessory after 10 mins air drying. A: human serum corresponding to the $<100 \mathrm{KDa}$ fraction (obtained after centrifugal filtration using the (unwashed) $100 \mathrm{~K}$ cut-off point filter); B: Milli-Q water after centrifugal filtration using the (unwashed) $100 \mathrm{~K}$ cut-off point filter and $\mathrm{C}$ : glycerol. Their respective high wavenumbers regions are plotted in $D, E$ and $F$. Spectra are offset for clarity

Notably, the peaks observed in the spectrum of the Milli-Q water correspond to those seen in spectra collected from a solution of pure glycerine (peak assignments also listed in Table 1), with weak contributions of residual water at $\sim 1675 \mathrm{~cm}^{-1}$ (Figure 3C). Successive spinning of Milli-Q water through the same filter demonstrates that the amount of glycerine in the filtrates collected decreases according to the number of 
centrifugation cycles, such that the contamination becomes negligible after the $4^{\text {th }}$ cycle, indicating the possibility to wash off the traces of glycerine with water (figure 4).

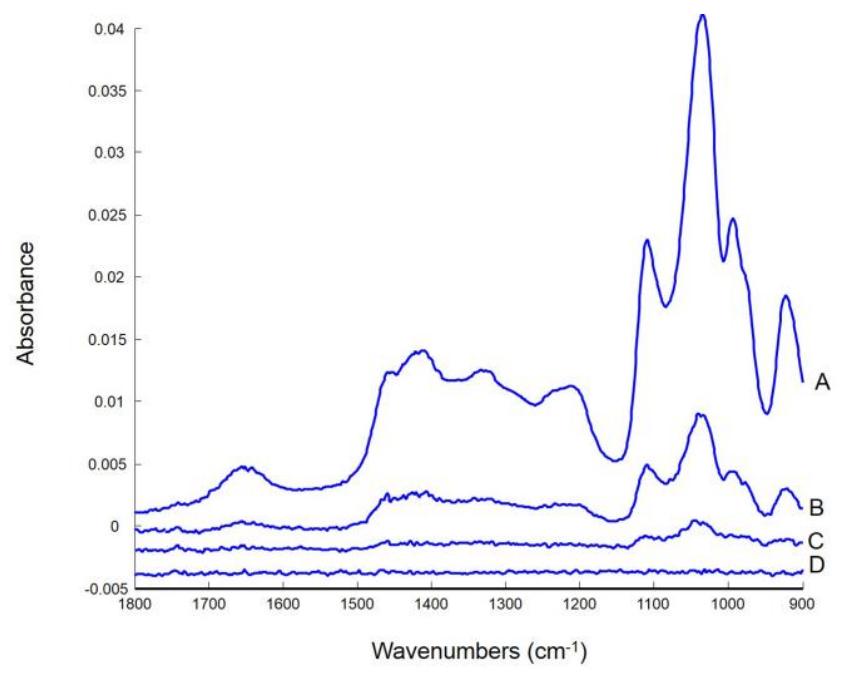

Figure 4: Infrared spectra collected using the UATR accessory collected from the filtrate from Milli-Q water after 10 mins air drying. The unwashed filter has been topped up with Milli- $Q$ water between each centrifugation and the filtrate collected in separate Eppendorfs. A: first centrifugation; B: Second centrifugation; C: Third centrifugation and D: Fourth centrifugation. Spectra are offset for clarity

Although the manufacturer's instructions specify that traces of glycerine can be found on the ultrafiltration membranes, the recommendations for their washing are rather imprecise: "If these materials interfere with analysis, pre-rinse the device with buffer or Milli-Q water. If interference continues, rinse with $0.1 \mathrm{~N} \mathrm{NaOH}$ followed by a second spin of buffer or Milli-Q water" (http://www.millipore.com/catalogue/module/c82301\#1) and no recommendations of spinning times, speed, volumes and repetition are provided. After testing different protocols, it has been found that the most efficient washing was achieved by spinning the devices with $\mathrm{NaOH}$ (once) and Milli-Q water (twice) for 30 mins at $14000 \mathrm{~g}$. The process was followed by a spinning with the centrifugal devices upside down at $1000 \mathrm{~g}$ for 2 mins in order to remove any residual solution contained in the filter. 
Using a $0.1 \mathrm{M} \mathrm{NaOH}$ solution, decontamination of the filters can be achieved more efficiently. While Milli-Q water alone requires 4 cycles, when washing the filters first with $\mathrm{NaOH}$ followed by rinsing with Milli-Q water, the traces of glycerine are completely removed from the filtrate after only 2 water rinse spinning cycles. However, the main concern when using $\mathrm{NaOH}$ is whether another source of molecular contamination is introduced in the data. Therefore, it is also crucial to verify that no traces of salt can be found in the data collected. The $\mathrm{pH}$ of the filtrates was monitored at the progressive points in the protocol. The $\mathrm{pH}$ of the $\mathrm{NaOH}$ solution and filtrate was found to be 13.5. After a first subsequent rinse with Milli-Q water, the $\mathrm{pH}$ of the filtrate was found to be 9. After a second rinse, the $\mathrm{pH}$ was found to be 7 . Subsequently, a blank sample containing only Milli-Q water has been processed through the washed filters instead of the human serum. The data presented in figure $5 \mathrm{C}$ clearly highlight that, as seen in figure $4 \mathrm{D}$, no traces of glycerine (Figure 3) or $\mathrm{NaOH}$ (Figure 5A) can be seen.

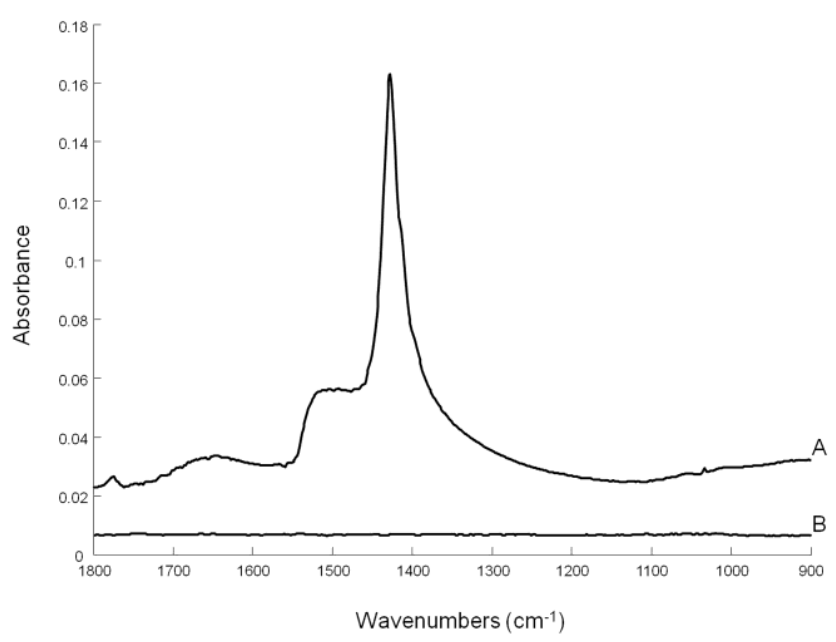

Figure 5: Infrared spectra collected using the UATR accessory collected after 10 mins air drying. A: washing solution of $\mathrm{NaOH}(0.1 \mathrm{M})$; B: Milli-Q water processed through a centrifugal filter washed using $\mathrm{NaOH}$. Spectra are offset for clarity

Using appropriate washing and rinsing procedures, the analysis of high and low molecular weight fractions can be achieved with a higher specificity and without 
interferences from the glycerine and any other contaminant, as shown in figure 6, which compares the ATR spectra of the high fraction from a washed 100k (A) centrifugal filter with that of the true, uncontaminated low molecular weight fraction from a washed 10k filter (B).
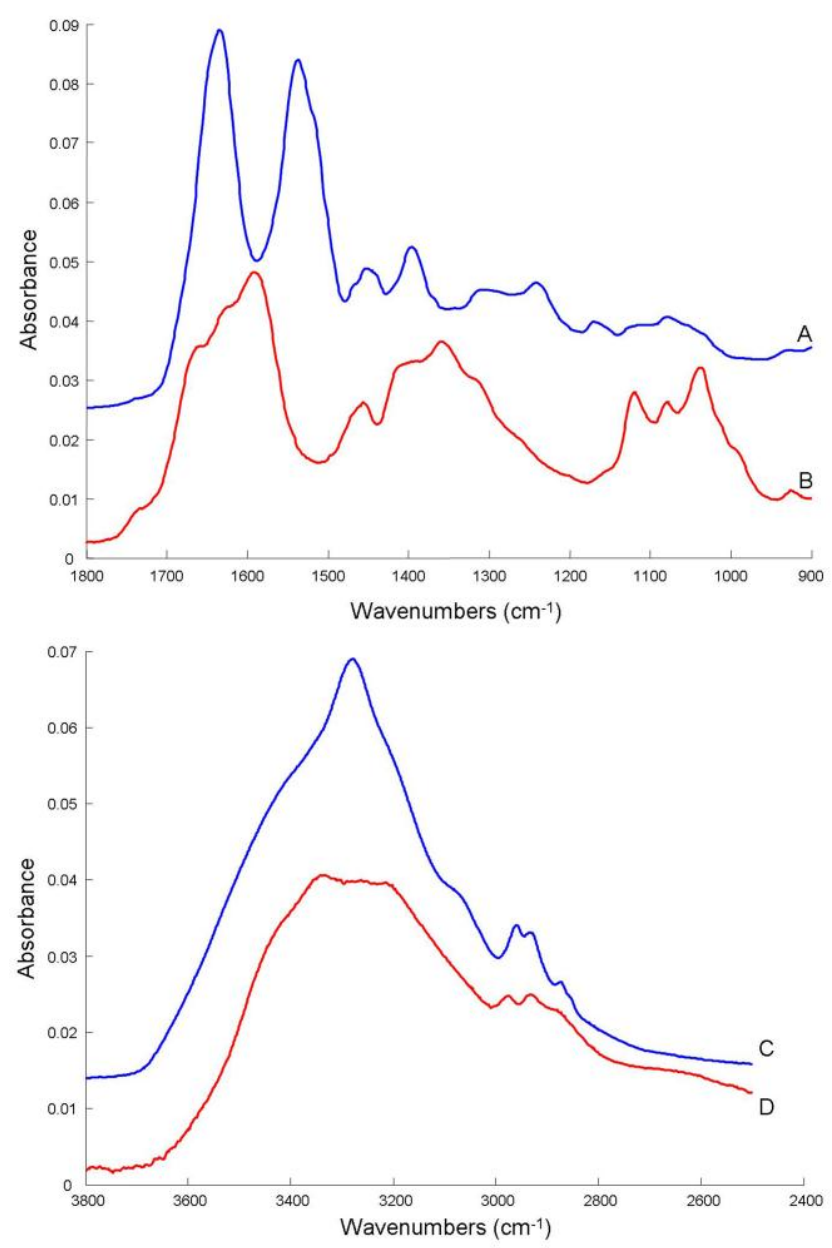

Figure 6 : Infrared spectra collected using the UATR accessory after 10 mins air drying. A: Human serum concentrate after centrifugal filtration using the washed $100 k$ device concentrate; B: Human serum concentrate after centrifugal filtration using the washed $10 \mathrm{k}$ device concentrate. Their respective high wavenmuber regions have been displayed in $C$ and D. Spectra offset for clarity

\section{Discussion}

A growing concern with vibrational spectroscopy is the absence of suitable controls when performing analysis. In most studies, the so-called normal samples are used as controls. However, as for colorimetric, dye based techniques, used for biomedical 
application such as flow cytometry and in vitro cytotoxic assays, controls in the absence of active agents with only the monitoring reagents have to be also measured to make sure no false positives are recorded.

This is also the case for the spectroscopic analysis of filtered bodily fluids. As mentioned in the manufacturer's guidelines, traces of glycerine are present on the filter membrane, requiring washing prior to use, depending on the sensitivity of the analysis performed. Therefore, in the present case using centrifugal devices for analysis of bodily fluids using vibrational spectroscopy, additional controls containing only deionized water have to be prepared under the same conditions in order to verify that the washing is complete, and that no molecular contamination of the samples occurred. Although when applied to the concentration of biological samples containing antigens, antibodies, enzymes or DNA, rigorous elimination of the trace amounts of glycerine may not be necessary, vibrational spectroscopies are highly specific techniques, delivering a molecular finger print of the samples.. When applied to the analysis of human serum, the main interest remains the possibility to remove the highly abundant proteins with high molecular weights to reveal the smaller proteins or peptides potentially usable as biomarkers. As a result, the low molecular weight proteins are present in relatively small concentrations in the different fractions collected which, according to the data presented in figure 3 , are even lower than the amount of trace glycerine collected from the filtering devices. This explains why glycerine features can appear prominently in spectra of centrifugally filtered fluids collected without performing an appropriate washing of the filters. Although the use of centrifugal devices is a promising approach for the field of vibrational spectroscopy applied to body fluids based diagnosis, the relevancy of preliminary studies that can be found in the literature is questionable due to the presence of molecular 
contamination of the samples by glycerine following ultra-filtration, obviously greatly reducing the accuracy of the analysis ${ }^{24,39,40}$. The true spectrum of the filtrate fraction is only achievable after appropriate decontamination. Although no attempt has been made to quantify the spectral features related to the constituent components in the serum, the study rather demonstrates that, using such centrifugal fractionation, potentially ultimately for medical diagnostics, it is essential to ensure that the washing protocols are optimised to avoid contamination of the sample. Glycerine itself has similar chemical moieties to peptides and proteins and thus the spectral profile overlaps that of the biomolecules of interest and thus rigorous elimination of the contamination is necessary.

\section{Conclusion}

The use of commercially available, Amicon ultra- 0.5 centrifugal filter devices (Millipore - Merck, Germany) for application of vibrational spectroscopy to disease diagnostics purposes is perfectly suitable. However, to ensure relevancy of the results, it is crucial that the filtration devices are carefully washed beforehand to avoid any molecular contamination. Delivering a specific molecular fingerprint of the samples analysed, it is crucial to perform the measurements with all the suitable controls to validate the observations made and increase the relevancy of the data set collected. It has been shown that, due to the specificity of the techniques, the washing requirements are more rigorous than those prescribed by the manufacturers. However, as long as appropriate preparation protocols are established, such devices will contribute to expediting the realization of real clinical applications for spectroscopic analysis of bodily fluids. 


\section{Acknowledgements}

This research was supported by the National Biophotonics and Imaging Platform (NBIP) Ireland, Higher Education Authority PRTLI (Programme for Research in Third Level Institutions) Cycle 4, co-funded by the Irish Government and the European Union Structural Fund and by Science Foundation Ireland under Grant Number 11/PI/08. 


\section{References}

1. Shaw RA, et al.in Encyclopedia of Analytical Chemistry, Meyers RA, John Wiley \& Sons, Chichester, 2006,

2. Huleihel M, et al., Spectroscopy 2005, 19 101-108.

3. Pichardo-Molina JL, et al., Lasers Med Sci, 2007, 22, 229-236.

4. Harris AT, et al., Head Neck Oncol, 2009, 1, doi: 10.1186/1758-3284-1181-1134.

5. Backhaus J, et al., Vibrational Spectroscopy 2010, 52 173-177.

6. Lin C-C, et al., Journal of Medical and Biological Engineering,, 2010, 30, 343-354.

7. Travo A, et al., Anal Bioanal Chem, 2014, DOI 10.1007/s00216-00013-07607-00215.

8. Scott DA, et al., Diabetol Metab Syndr, 2010, 2, doi: 10.1186/1758-5996-1182-1148.

9. Bispo JA, et al., J Biomed Opt, 2013, 18, 87004.

10. Khalil SKH, et al., Journal of Applied Sciences Research, , 2007, 3, 387-391.

11. Keating ME, et al., Nanomedicine (Lond), 2013, 8, 1335-1351.

12. Freudiger CW, et al., Science, 2008, 322, 1857-1861.

13. Bonifacio A, et al., Anal Bioanal Chem, 2014, 406, 2355-2365.

14. Yu Y, et al., Biochim Biophys Acta, 2014.

15. Bohme R, et al., J Biophotonics, 2010, 3, 455-461.

16. Dorling KM, et al., Trends Biotechnol, 2013, 31, 437-438.

17. Dazzi A, et al., Appl Spectrosc, 2012, 66, 1365-1384.

18. Good DM, et al., J Proteome Res, 2007, 6, 4549-4555.

19. Hu S, et al., Proteomics, 2006, 6, 6326-6353.

20. Adkins JN, et al., Mol Cell Proteomics, 2002, 1, 947-955.

21. Pieper R, et al., Proteomics, 2003, 3, 1345-1364.

22. Antman EM, et al., N Engl J Med, 1996, 335, 1342-1349.

23. Tirumalai RS, et al., Mol Cell Proteomics, 2003, 2, 1096-1103.

24. Hands JR, et al., Anal Bioanal Chem, 2013, 405, doi: 10.1007/s00216-00013-07163-

$\mathrm{Z}$.

25. Liotta LA, et al., J Clin Invest, 2006, 116, 26-30.

26. Petricoin EF, et al., Nat Rev Cancer, 2006, 6, 961-967.

27. Thadikkaran L, et al., Proteomics, 2005, 5, 3019-3034.

28. Zhang AH, et al., Appl Biochem Biotechnol, 2013, 170, 774-786.

29. Ray S, et al., Proteomics, 2011, 11, 2139-2161.

30. Apweiler R, et al., Clin Chem Lab Med, 2009, 47, 724-744.

31. Rohleder D, et al., J Biomed Opt, 2005, 10, 031108.

32. Poon KW, et al., Analyst, 2012, 137, 1807-1814.

33. Dorling KM, et al., Trends Biotechnol, 2013, 31, 327-328.

34. Hands JR, et al., J Biophotonics, 2014, doi: 10.1002/jbio.201300149.

35. Bonnier F, et al., J Biophotonics, 2013, doi: 10.1002/jbio.201300130.

36. Merrell K, et al., J Biomol Tech, 2004, 15, 238-248.

37. Roche S, et al., Proteome Sci, 2006, 4, doi: 10.1186/1477-5956-1184-1120.

38. Finoulst I, et al., J Biomed Biotechnol, 2011, 2011, 245291.

39. Petrich W, et al., Analyst, 2009, 134, 1092-1098.

40. Hughes C, et al., Journal of Biophotonics, 2014, DOI: 10.1002/jbio.201300167.

41. Barth A, Prog Biophys Mol Biol, 2000, 74, 141-173.

42. Garidel P, et al., BioProcess International, 2006, 4, 40-46.

43. Garidel P, et al., BioProcess International 2006, 4, 48-55.

44. Kongjao S, et al., Korean J. Chem. Eng., 2010, 27, 944-949.

45. Cho L-L, et al., Forensic Science Journal, 2012, 11, 33-40.

46. Meade AD, et al., Anal Bioanal Chem, 2007, 387, 1717-1728. 
47. Baker MJ, et al., Br J Cancer, 2008, 99, 1859-1866. 